\title{
A comparison of an intermittent versus continuous CS in classical conditioning of the nictitating membrane response of the rabbit'
}

\author{
James D. Papsdorf, Harold F. Fishbein and I. Gormezano
} INDIANA UNIVERSITY

\begin{abstract}
Abstraet
Thirty four Ss were randomly assigned to two groups conditioned to either an $1100 \mathrm{msec}$. continuous CS tone $(\mathrm{N}=17)$ or an intermittent, $50 \mathrm{msec}$. on and $50 \mathrm{msec}$. off, CS tone of $1100 \mathrm{msec}$. duration $(\mathrm{N}=17)$. Higher levels of conditioning were obtained in the pulsed CS group and the relevance of this finding to the stimulus trace hypothesis was discussed.
\end{abstract}

\section{Problem}

In Pavlov's studies of classical conditioning (Pavlov, 1927) extensive use was made of intermittent CSs (e.g., rotating discs, metronome, bubbling water). Although a direct comparison of the relative efficacy of an intermittent vs. continuous CS on the course of conditioning has not been made, it might be expected that intermittent stimuli would produce a greater number of afferent firings. According to Pavlov the strength of conditioning depends upon the intensity of the afferent state of affairs existing at the time of US onset. Hull $(1943,1952)$ also postulated that strength of conditioning is a function of the intensity of the trace present at the time of US occurrence; and Anderson (1960) reformulating the stimulus trace concept within the framework of statistical learning theory, made the similar suggestion that strength of conditioning is a function of the number of active CS elements coincident with US onset. Consequently, the stimulus trace hypothesis would lead to the prediction that an intermittent CS produces a higher level of conditioning than a continuous CS. The present investigation was concerned with making such a comparison.

\section{Method}

The apparatus and preparation employed in conditioning the nictitating membrane of the rabbit have been described in detail (Gormezano, 1964; Schneiderman \& Gormezano, 1964). Briefly, S was placed in a Plexiglass restraining box with his head inserted through an adjustable stock comprising the front of the box. Gross head movements were further reduced by fastening the pinna of both of Ss ears to the front of the stock with a foam rubber coated clamp. A muzzle-like assembly containing a stimulus air jet and rotary potentiometer was mounted on the animal's head. To permit recording of membrane movement and to insure continual exposure of the cornea, the superior and inferior eyelids of S's right eye were held back by means of stainless steel clasps. A silk thread was attached to a rod mechanically coupled to the shaft of the potentiometer and a small metal hook connected to the other end of the silk thread was attached to a nylon loop sutured in the nictitating membrane of S's right eye. The signals from the potentiometer, generated by movement of the membrane, were amplified and recorded by means of an Offner Dynograph.

Thirty four albino rabbits, 80-100 days old, were randomly assigned to either a Continuous CS group $(\mathrm{N}=17)$ wherein the CS consisted of a $1000 \mathrm{cps}$ tone having an intensity of $76 \mathrm{db}$ (relative to .0002 dynes $/ \mathrm{cm}^{2}$ ) or to an Intermittent CS group $(\mathrm{N}=17)$ conditioned to the same tone, except that the tone was repetitively interrupted, $50 \mathrm{msec}$. on and $50 \mathrm{msec}$. off, to produce a discontinuous train of tone pulses. The US consisted of a $100 \mathrm{msec}$. puff of compressed nitrogen with an intensity of $75 \mathrm{~mm}$ of $\mathrm{Hg}$ directed at the dorsal surface of the right cornea. The CS-US interval was $1000 \mathrm{msec}$. and the CS terminated with the offset of the US.

Prior to conditioning Ss received a 1-hr. adaptation session on each of two successive days. Immediately after the second adaptation session, Ss were sutured and $24 \mathrm{hr}$. later were given the first of 10 days of acquisition training. Each acquisition session consisted of 70 paired CS-US presentations at random intertrial intervals of 40,60 and $80 \mathrm{sec}$. with a $1 \mathrm{~min}$. average intertrial interval. A CR was defined as a pen deflection

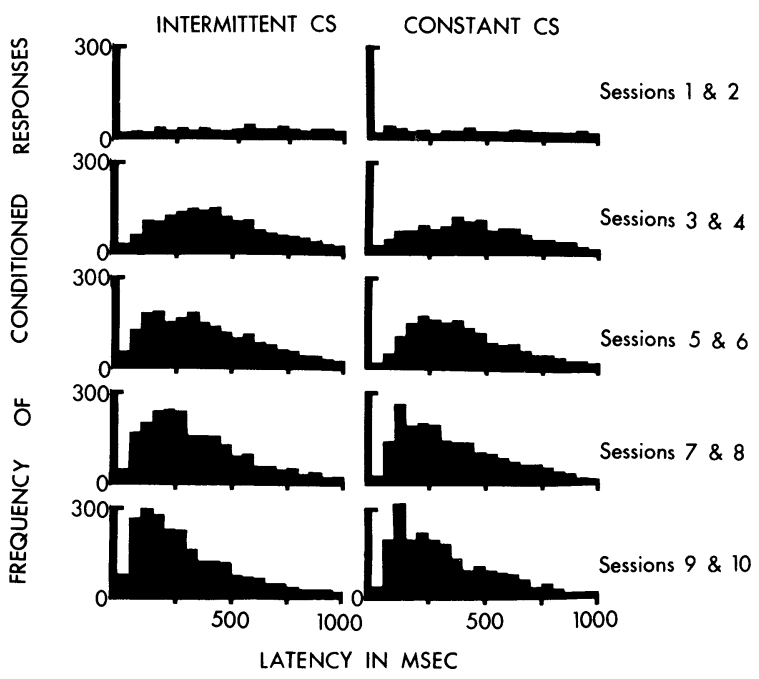

Fig. 1. The distribution of response latencies for the two experimental groups over successive two day blocks. 


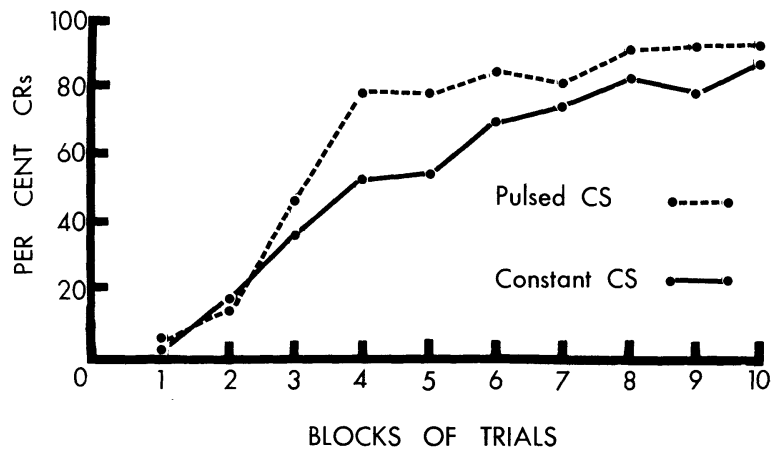

Fig. 2. The percentage CRs for the two experimental groups plotted in 70 trial blocks.

of at least $1 \mathrm{~mm}$ from baseline in the interval from $25 \mathrm{msec}$. after CS onset to the time of US onset.

\section{Results and Diseussion}

Figure 1 presents the distribution of response latencies for each of the experimental groups over successive two day blocks. Examination of the figure reveals that both groups demonstrated a progressive decrease in modal latency over the first six acquisition sessions and a stabilization of these modal latencies over the last four sessions. Modal latency appeared to decrease more rapidly for the Intermittent CS group, attaining a value of $125 \mathrm{msec}$. by the sixth acquisition session. The group acquisition curves of Fig. 2 plotting per cent CRs over each 70 trial conditioning session, indicate that not only does the Intermittent CS group attain a higher asymptote of about $90 \%$ but that it does so more rapidly. An analysis of variance on percentage CRs over the last seven acquisition sessions yielded a significant $F$ ratio for Experimental Conditions (F, 4.56; df, $1 / 32 ; p<.05)$, indicating that the difference in the conditioning levels of the two groups was reliable, while the Trials $\mathrm{x}$ Experimental Conditions interaction fell short of significance (F, 1.75; df, 9/288; $p<.10)$.

The superiority of the Intermittent CS group lends support to the stimulus trace formulation (Anderson, 1960; Hull, 1943, 1952; Pavlov, 1927). However the differential conditioning hypothesis that inhibition generated by nonreinforced responding in the intertrial interval generalizes less to those CSs which are increasingly different from background stimulation can provide an alternative theoretical interpretation of the superiority of the intermittent CS. The differential conditioning hypothesis, developed by Perkins (1953), Logan (1954) and Champion (1962), postulates that manipulation of CS intensity does not operate through Stimulus Intensity Dynamism (V) on the habit factor or through strength of neural traces but simply in terms of increasing the discriminability of the CS from background stimuli. The present finding does not provide differential support for either of these two formulations. A possible method for assessing the validity of either formulation to the role of an intermittent CS in conditioning would be to compare the performance obtained under the procedure in which the intermittent stimulus is present during the intertrial interval with no stimulus as the CS, with that obtained in conditioning to the intermittent $\mathrm{CS}$ and no intertrial stimulation (Champion, 1962). If the differential conditioning hypothesis is correct, there should be no difference between the two conditions, but if the trace notion is correct, onset of the intermittent tone as the CS should produce better conditioning. We plan to embark upon such an investigation employing appropriate contrast groups.

\section{References}

ANDERSON, N. H. Response emission in time with applications to eyelid conditioning. In R. R. Bush \& W. K. Estes (Ed.), Studies in mathematical learning theory. Stanford: Stanford Univer. Press, 1959. Pp. 125-134.

CHAMPION, R. A. Stimulus-intensity effects in response evocation. Psychol. Rev., 1962, 69, 428-449.

GORMEZANO, I. Classical conditioning. In J. B. Sidowski (Ed.), Experimental methods and instrumentation in psychology. New York: McGraw-Hill, 1964, in press.

HULL C. L. Principles of behavior. New York: Appleton-Century, 1943.

HULL, C. L. A behavior system. New Haven: Yale Univer. Press, 1952.

LOGAN, F. A. A note on stimulus intensity dynamism (V).Psychol. Rev., 1954, 61, 77-80.

PERKINS, C. C., JR. The relation between conditioned stimulus intensity and response strength. J.exp. Psychol., 1953, 46, 225-231.

SCHNEIDERMAN, N., \& GORMEZANO, I. Conditioning of the nictitating membrane of the rabbit as a function of CS-US interval. J.comp. physiol. Psychol., 1964, 57, 188-195.

\section{Note}

1. This research was supported by Grant GB-2843 from the National Science Foundation. 